\title{
Industrial Management Approaches for Improving Material Control in Building Services Works
}

\author{
Sammy K. M. Wan \\ Analogue Group of Companies, Hong Kong \\ Mohan M. Kumaraswamy \\ Department of Civil Engineering, The University of Hong Kong, Hong Kong
}

\begin{abstract}
Purpose - Given increasing user aspirations for comfort, connectivity, health, safety and security, the building services subsector now plays an even greater role in construction. It also contributes heavily to construction debris. Hypothesising that improved material control can help reduce construction debris considerably, this paper investigates relevant critical production shortcomings that generate construction debris in building services works.

Design/methodology/approach - Relevant previous research studies on main causes of wastes are first reviewed. Findings from brainstorming exercise at a focus group meeting provide the basis for a series of structured face-to-face interviews with experienced site supervisors. The subsequent analysis of interview findings together with deductive reasoning, lead to the development of the proposed improvement strategies.

Findings - The most significant causes of production shortcomings identified in the study are 'poor coordination of processes or trades', 'inappropriate site storage' and 'inadequate protection of materials'. Industrial management principles help to develop suitable building services storage principles and to propose an industrial flow pattern incorporating barcoding and RFID tracking technologies.
\end{abstract}

Research limitations/implications - These findings are a useful comparative reference for other countries, where the study methodology may be replicated to generate region-specific findings.

Originality/value - By applying the suggested proposals at the material control stage, this important, but little studied subsector can both reduce production shortcomings, and help lessen the burden on local landfills by reducing 'conflicts' between competing resources and storage areas, and by the early mobilization of specialist contractors to resolve uncertainties and reduce rework.

Keywords: Barcoding, Building services, Coordination, Construction debris, Hybrid push-pull system, Material control

Classifications: Research paper

\section{Introduction}

Construction debris is becoming a pressing environmental problem, for example when 
considering limits on the remaining lifespans of current landfill sites in Hong Kong. In 2007, nearly 14 million tonnes of solid waste were created and about $21 \%$ or 2.9 million tonnes are landfilled construction debris (EPD, 2008). Of these, the majority of construction wastes in building services products, such as considerable amounts of fittings and accessories as suggested by Olnhoff and Martin (2003) in the 'BSRIA Guide - BG 16/2003' are deposited in landfills. Viewed from this angle, the debris mountain created by the building services subsector is huge and it continues to grow rapidly. If this trend continues, the Hong Kong landfill and public fill sites will be filled up in 2010 (EPD, 2007).

Illingworth (2000) contended that specialist contractors appear to have no incentive to avoid waste or protect materials if the main contractor procures the materials for labour-only specialist contractor. Material costs constitute more than $40 \%$ of the total construction cost and their control is one of the important factors for the success of a construction project (Lee, 2004). The percentage appears to be much higher in the building services subsector (that includes many specialist contractors) taking into account the considerable amount of electrical and mechanical equipment to be installed in this subsector. Because of this, material control is crucial for building services installations that are subject to many uncertainties, contributors and dependencies. It is commonly accepted that an extra 5-10\% of materials should be ordered to allow for site wastage through damage, spillage, over-supply and vandalism (Coventry and Woolveridge, 2002). There is therefore a dire need to properly handle the materials in this subsector not only to cut the extra materials ordered but also to minimize the material wastes and ultimately reduce construction debris to be landfilled.

Other contributors to construction debris usually arise from poor production management practices. This paper describes the major findings part of a study that investigated the critical inadequacies of different construction processes arising at three key stages in the building services subsector. This paper focuses on the material control stage, while pre-installation and site installation stages warrant different approaches that will be dealt with separately. This paper first reviews relevant research studies on main causes of material wastes that contribute to construction debris. Next, a series of interviews with 15 experienced frontline site supervisors involved with building services works in Hong Kong are presented, discussed and analyzed. The results contribute to an identification of critical causes of production shortcomings in building services projects at the material control stage. Deductive reasoning leads to the development of suitable building services storage principles. The paper then conceptualises and illustrates, with reference to industrial management arrangement and modern technologies, a 'Material Tracking System' and 'hybrid push-pull system' that may reduce 'conflicts' between competing resources and storage areas for on-site delivery, storage and installation. A parallel benefit is noted in mobilizing specialist contractors to participate in 
resolving design uncertainties and clarifying design intent at an early stage.

\section{Literature review}

Materials wastes can also be divided into design, taking-off and ordering, supply and contract wastes (Illingworth and Thain, 1998; Illingworth, 2000). Many researchers have previously noted the potential interrelationship between material wastes and construction debris in the construction industry. Over 30 years ago, Skoyles (1976) admitted that there is an unacceptable level of construction debris that can only be reduced through a significant upgrade in the production system. Gavilan and Bernold (1994) observed and analyzed different construction processes and categorized the sources of construction debris into 'design, procurement, handling of materials, operation, residual and others not listed'. Vaid (1996) indicated, in his productivity study on mass housing projects, that poor design, material mismanagement and non-commitment of site personnel are the main causal factors of the high levels and rates of construction debris. Bossink and Brouwers (1996) investigated the prevention of construction debris wastes in the Netherlands and suggested that the main causes of construction debris are related to upstream processes such as design and material handling. Faniran and Caban (1998) revealed a similar result from his survey and categorized typical construction debris sources into design change, design error, leftover material scrap, packaging and non-reclaimable consumables and poor weather. Formoso et al. (2002) pointed out in their study on the Brazilian building industry, that most of the construction debris could be avoided by implementing managerial improvements.

All the above studies indicate that construction debris can be reduced through process improvements throughout the entire construction cycle. It has long been contended in the manufacturing industry that an 'industrial production' philosophy is crucial for production waste reduction and the outcome of this reduction is an enhanced and smoothened flow of work within the production cycle (Schonberger, 1990; Plossl, 1991). By identifying constraints at the material control stage in building services work in the construction industry, these industrial management principles are equally applicable for reducing production wastes at this stage. Furthermore, it could result in the reduction of materials wastes and ultimately reduce construction debris to be landfilled. Meanwhile, most of the researchers acknowledge that both 'design' and 'material handling' have major influence on materials wastes. However, previous studies and/or publications on material control practices are very limited (Thomas et al., 1998, 1999, 2005), and it seems that no previous studies have probed the even more complex, uncertain and labour intensive building services subsector of the construction industry (Ekanayake and Ofori, 2004).

As illustrated by Thomas et al. (2005), site material management is defined as the allocation 
of delivery, storage and handling, spaces and resources for the purposes of supporting the labour forces and minimizing inefficiencies due to congestion and excess material movement. The authors established that semi-permanent (exterior) storage, staging and workface (interior) storage zones have unique functions related to site material management. It is therefore important to investigate if the principles are also applicable to the building services subsector. On the other hand, risk of interference and coordination problems among specialist contractors working concurrently in building projects is not negligible (Tommelein and Ballard, 1997; Riley and Horman, 2001). Suitable principles arising from deductive reasoning for reducing 'conflicts' between competing resources and storage areas for on-site delivery, storage and installation in building services subsector are crucial, although further research is needed to develop the detailed proposal.

\section{Survey of causes of production shortcomings at material control stage}

In order to translate suitable industrial management principles into practice, it is necessary to identify and reduce the critical production shortcomings, including their causes that contribute to construction debris over the whole construction process of a building services project. It is also valuable to identify all the root causes of construction debris before targeting their minimisation, since much construction debris need not arise in the first place (Gavilan and Bernold, 1994; Snook et al., 1995). However, this paper focuses solely on presenting and discussing the results obtained at the material control stage, while a subsequent paper will focus on the ‘site installation' stage.

Before arranging a structured interview survey with frontline site supervisors, a brainstorming exercise was performed in 2006 with a specially convened focus group meeting of 10 senior and mid-level construction practitioners including the first author so as to identify the common and potentially serious production factors that adversely affect performance levels over the whole process of a building services project. The responses and comments received via the brainstorming exercise were reviewed in the light of relevant studies and available sources of reference for developing the planned structured interview survey. The results of the exercise were recorded in a cause and effect (Ishikawa) diagram that aims to map the linkages between causes and effects. This diagram was used as the main reference tool when preparing for and conducting the survey interviews, observations and dialogues with frontline site supervisors.

Targeting deeper experiential knowledge, structured face-to-face interviews were conducted with 15 experienced site supervisors, each having around 8 to 17 years of on-site experience on building services projects as shown in Table I. A 5-point Likert scale that was designed to determine the views of the supervisors, and whether these findings exhibited commonalities 
as well. Site observations were conducted in parallel with the site supervisors' interviews to unearth deeper insights in this study. The interviewees were asked to comment on the 'frequency' of occurrence of production shortcomings and also on the 'importance' of contributions to construction debris arising from these causes of production shortcomings at different construction stages. The 'Relative Significance Index' or 'RSI' ranking technique, as used in numerous construction management research projects was now adopted (Kometa et al., 1994; Tam et al., 2000) was applied to evaluate the overall rankings. The numerical score of each cause was transformed to RSI in order to assess the relative ranking of causes with formula:

$$
\text { Relative Significance Index }(R S I)=\frac{\sum_{\mathrm{i}=1}^{\mathrm{n}} \mathrm{W}_{\mathrm{i}}}{\mathrm{N} \times \mathrm{W}_{\mathrm{H}}} \quad \text { where }(0 \leq \mathrm{RSI} \leq 1)
$$

where $W_{i}$ is the weighting of each cause as rated by the interviewees ranging from 1 to $5, N$ is the total number of interviewees, and $\mathrm{W}_{\mathrm{H}}$ is the highest weight (i.e. 5) adopted in the survey.

Table I. Profile of the interviewees

\begin{tabular}{cccc}
\hline $\begin{array}{c}\text { Number of } \\
\text { interviewees }\end{array}$ & Trade of building services subsector & $\begin{array}{c}\text { Avg. on-site } \\
\text { experience } \\
\text { (Yr) }\end{array}$ & $\begin{array}{c}\text { Percentage } \\
\text { (\%) }\end{array}$ \\
\hline 3 & E\&M supervision in main contractor & $10-15$ & 20.0 \\
2 & E\&M consultant & $13-14$ & 13.3 \\
1 & E\&M package contractor & 17 & 6.7 \\
2 & Electrical system & $13-15$ & 13.3 \\
1 & Fire services engineering & 14 & 6.7 \\
2 & Heating, ventilation \& air-conditioning & $9-13$ & 13.3 \\
1 & Plumbing \& drainage & 16 & 6.7 \\
1 & Lift escalator & 10 & 6.7 \\
1 & Building automation & 15 & 6.7 \\
\hline
\end{tabular}

The analysis next combined the RSIs in the 'frequency' and 'importance' categories, in order to compute a 'Potential Significance Index' or 'PSI'. The PSI of each cause of production shortcomings was formulated to assess the ranking taking into account the frequency of occurrence of the causes and the importance of contributions to construction debris arising from the causes. Weighting assigned to 'frequency' and 'importance' took into account that the frequency of occurrence of production shortcomings was considered more significant by the interviewees. More than $70 \%$ of them agreed to weight 'frequency' as 0.65 with a 
correspondingly lower weighting of 0.35 for 'importance' of contribution to construction debris from that cause.

The PSI was computed by summing up the two respective weighted RSIs with the use of the following proposed formula:

Potential Significance Index $(P S I)=R S I_{F} \times 0.65+R S I_{I} \times 0.35 \quad$ where $(0 \leq \mathrm{PSI} \leq 1)$

Table II shows the $R S I_{\mathrm{F}}$ and $R S I_{\mathrm{I}}$ values that indicate the Relative Significance Index of 'frequency' and 'importance' along with the PSI values computed as above.

It is found that 'poor coordination of processes or trades' (M01), 'inappropriate site storage' (M11) and 'inadequate protection of materials' (M10) are the three most critical causes of production shortcomings at the material control stage of the building services work, where the $P S I$ values approximate to 0.6 as perceived by the interviewees in the study.

Table II. The RSIs of causes of production shortcomings at material control stage

\begin{tabular}{|c|c|c|c|c|c|c|c|c|c|}
\hline \multirow[t]{2}{*}{ Item } & \multirow[t]{2}{*}{ Description of causes } & \multicolumn{3}{|c|}{ Frequency } & \multicolumn{3}{|c|}{ Importance } & \multicolumn{2}{|c|}{ Significance } \\
\hline & & $\begin{array}{l}\text { Std. } \\
\text { dev. }\end{array}$ & RSI & Rank & $\begin{array}{l}\text { Std. } \\
\text { dev. }\end{array}$ & RSI & Rank & PSI & Rank \\
\hline M01 & Poor coordination of processes or trades & 0.69 & 0.6 & 2 & 0.93 & 0.57 & 2 & 0.59 & 1 \\
\hline M02 & Poor layout for material handling & 0.79 & 0.62 & 1 & 0.45 & 0.46 & 7 & 0.56 & 4 \\
\hline M03 & Unnecessary, excessive or incorrect materials & 0.82 & 0.56 & 6 & 0.82 & 0.56 & 3 & 0.56 & 5 \\
\hline M04 & Defective incoming materials & 0.78 & 0.42 & 14 & 1.27 & 0.68 & 1 & 0.51 & 6 \\
\hline M05 & Delay in transportation & 0.66 & 0.55 & 7 & 1.32 & 0.4 & 9 & 0.50 & 7 \\
\hline M06 & Damage during transportation & 0.51 & 0.51 & 9 & 0.99 & 0.46 & 6 & 0.49 & 9 \\
\hline M07 & Waiting for instructions & 0.71 & 0.52 & 8 & 0.67 & 0.36 & 13 & 0.46 & 11 \\
\hline M08 & Excessive receiving inspections & 0.88 & 0.41 & 16 & 0.51 & 0.34 & 15 & 0.39 & 15 \\
\hline M09 & Lack of facilities for material handling & 0.71 & 0.5 & 10 & 0.44 & 0.45 & 8 & 0.48 & 10 \\
\hline M10 & Inadequate protection of materials & 0.71 & 0.6 & 3 & 0.7 & 0.53 & 5 & 0.58 & 3 \\
\hline M11 & Inappropriate site storage & 0.71 & 0.59 & 4 & 0.83 & 0.55 & 4 & 0.58 & 2 \\
\hline M12 & Ineffective manual handling & 0.62 & 0.56 & 5 & 0.93 & 0.38 & 12 & 0.50 & 8 \\
\hline M13 & Loss of materials & 0.49 & 0.47 & 12 & 1.12 & 0.4 & 9 & 0.45 & 12 \\
\hline M14 & Ineffective or unclear communication & 0.52 & 0.49 & 11 & 0.43 & 0.35 & 14 & 0.44 & 13 \\
\hline M15 & Duplication or inconsistent information or instructions & 0.53 & 0.46 & 13 & 0.71 & 0.39 & 11 & 0.44 & 14 \\
\hline M16 & Bureaucracy of work procedures and forms & 0.35 & 0.42 & 15 & 0.47 & 0.26 & 16 & 0.36 & 16 \\
\hline
\end{tabular}


Apart from calculating the relative significance ratings, the degree of correlation between the rank-order of $R S I_{\mathrm{F}}$ and $R S I_{\mathrm{I}}$ was checked statistically by means of the Spearman's rank-order correlation coefficient $\left(r_{s}\right)$ (Levin and Fox, 2003) as set out by the following formula:

$$
r_{s}=1-\frac{6 \times \sum d^{2}}{n \times\left(n^{2}-1\right)}
$$

where $r_{s}$ is the rank-order correlation coefficient, $d$ is the difference in rank between $R S I_{\mathrm{F}}$ and $R S I_{I}$ and $n$ is the total number of cases or causes, which was 16 in this study. The level of significance or $\alpha$ was set at 0.05 . The $r_{s}$ varies between +1 and -1 , where +1 implies a perfect positive relationship while -1 results from a perfect negative relationship (Assaf and Al-Hejji, 2006). If the $r_{s}$ value is larger than 0.506 at 95\% confidence interval, the correlation between $R S I_{\mathrm{F}}$ and $R S I_{\mathrm{I}}$ is positive. The resultant $r_{\mathrm{s}}$ value was 0.510 in this case indicated a rather slight positive correlation. It could be concluded that the interviewees who ranked $R S I_{\mathrm{F}}$ high also tended to rank $R S I_{I}$ high. However, the two RSI groups were not significantly correlative (Chang, 2007), indicating some exceptions.

\section{Survey results and discussions}

Figure 1 shows that the RSI of 'frequency' is approximately and comparably higher than the 'importance' as rated by the interviewees, except for items M03 and M04, which could represent the abovementioned exceptions that limited the above $r_{s}$ value. This reveals that most of the site supervisors made their judgement based on their site experience and are usually more conservative to judge importance of the causes that contribute to construction debris in the course of their works. As depicted in Table II, 'defective incoming materials' or M04 is the most important factor or cause at the material control stage. It is understandable that any defective material is disposed of, as construction debris at landfills but only a few of the site supervisors indicated that handling of these materials takes extra time, effort and resources that may ultimately slow down the overall construction progress. One site supervisor stated that any defective incoming bathtubs and latrines will mostly be disposed of as construction debris and he explained that only a few of the materials can be directly delivered to, and sorted at the point of use and therefore are handled more than once. This may increase the probabilities of material defects. However, the RSI of 'frequency' of this item is comparably low as clearly seen in the black 'up-down bar' in Figure 1. The interviewees may perceive that the word, 'defective', is strong and will inevitably contribute to material wastes and construction debris but this cause may not occur frequently in their building services projects because of the superior logistical and transportation systems and comparatively stringent incoming inspections in Hong Kong. 
Figure 1. Distribution of RSIs of 'Frequency' and 'Importance' at material control stage

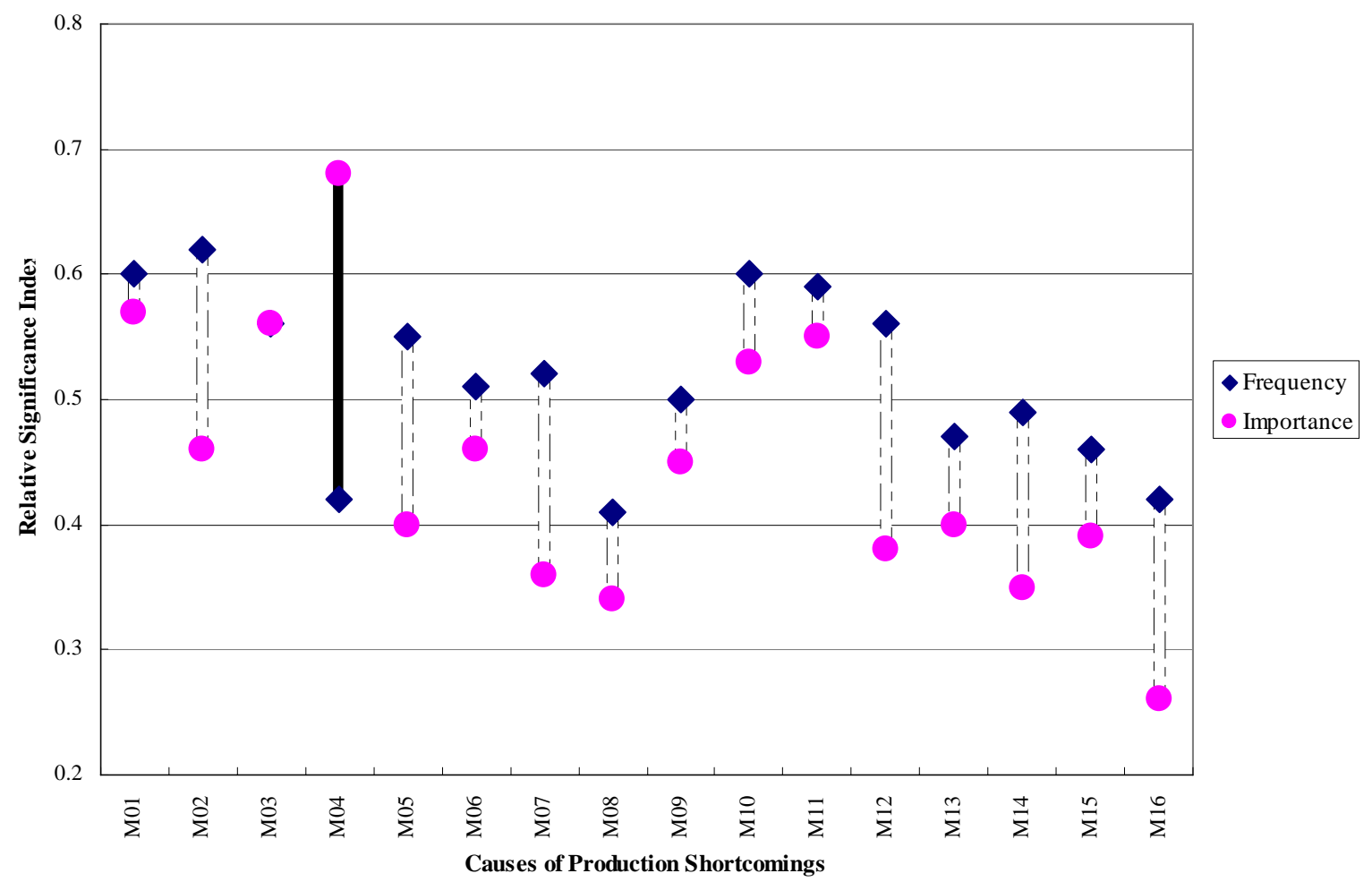

On the other hand, it was identified that 'poor layout for material handling' or M02 in respect of on-site material storage and handling was rated highly as a major cause that frequently occurs in projects. Even though this factor was not highly rated as an important factor that contributes to construction debris, it is believed that the layout is probably arranged by the main contractor or other upstream parties, and the lack of coordinated planning with subcontractors for material handling leads to argument, waiting, interference with other trades and even damage to materials and equipment. Some $93 \%$ of the interviewees agreed that it was time consuming to collect and transport materials, tools and equipment as most of them were delivered and deposited in such a random manner. A few interviewees opined that most of the on-site storage areas were temporary, uncertain and poorly protected. Such poorly thought out on-site storage and repetitive handling of materials caused interference with other crews and an increased risk of material damage, deterioration and misuse. This also explains why 'inappropriate protection of materials' or M10 was rated as the third most critical cause that might frequently occur in the work. Meanwhile, 'poor coordination of processes' or M01 was rated as the second major cause as reflected in the RSIs of both 'importance' and 'frequency'.

The last-mentioned finding also seems to support the findings of Tommelein and Ballard (1997) who also found that coordination of specialist contractors is a challenging task, as most of them perform work concurrently and compete for site resources. Meanwhile, the 
results seem to indicate that the risk of interference problems is highest on building projects that have intensive building services requirements as suggested by Riley and Horman (2001). One of the principal reasons for this is the frequent conflicts between trades, in particular of false ceilings, horizontal and vertical ducts and/or pipes and conduit works, especially when fitting into tight spaces and routing in inefficient configurations. More importantly, some trades will try to work fast to prevent being trapped in the critical path and being held responsible for the liquidated damages in case of delay, although the exact locations of various services are not clearly defined on the drawings. Other interdependent trades may then have to modify the installed works and/or procured materials and this contributes to construction debris arising out of reorder, demolition, replacement, modification and rework.

From another angle, it is also useful to consider and compare the corresponding results identified at the procurement stage but these outside the scope of this paper. More than $70 \%$ of the site supervisors interviewed commented that design changes can cause variations to previously approved equipment submissions, and those can well affect their procurement. It is commonly accepted that an extra 5-10\% of materials should be ordered to allow for site wastage through damage, spillage, over-supply and vandalism (Coventry and Woolveridge, 2002). Even the 'unnecessary, excessive or incorrect materials' (M03) was rated as the third most important cause at the 'material control' stage, it is believed that much of the incorrect equipment will not contribute to construction debris, as most equipment in the Hong Kong building services subsector will be finalised and purchased by the site engineers at the 'eleventh hour' and even delivered before a purchase order can be processed. The interviewees may have perceived that the words, 'unnecessary, excessive or incorrect', are strong and will inevitably contribute to material wastes and construction debris. When discussed in detail, it was revealed that in case of any incorrect procurement, the equipment can be returned to the suppliers or retained for other construction projects. If so handled, even in such a non-value-adding process, there is no additional debris in such cases. Of course, the unnecessary, excessive or incorrect small pipe fittings and sundries may impact to a certain extent on the construction debris. It is necessary to mention that a few interviewees pointed out that the procurement and delivery at the 'eleventh hour' occurs frequently because of the lack of confidence in the approval instructions of the consultants or other upstream parties. As a result, the materials/equipment are often suddenly carelessly unloaded and distributed at temporary work areas, but not directly taken to the point of use, or to planned strategic locations, that take into account proper access paths and sufficient handling means. All these might contribute to double handling, damage and vandalism as well.

On the other hand, frequent changes or errors in design can still contribute to construction debris at the 'purchasing and subcontracting' stage, because much extra time is spent by the 
site supervisors for investigating, administering and coordinating these varied procurement works, while on-site monitoring of the installation activities may be delegated to inexperienced or unskilled foremen. This can therefore contribute to more defective works or even reworks as the inexperienced or unskilled foremen may not be capable of identifying minor defects at the source before turning into large defective works. Meanwhile, design changes and/or errors also cause variations to early installed works such as conduit routing, ductwork, pipework, trunking, etc. Their modification, demolition or replacement works will inevitably contribute to construction debris. It is worthwhile to mention that at the 'purchasing and subcontracting' stage, 'wrong selection of suppliers or subcontractors' is one of the major items that contribute to construction debris because substandard suppliers or subcontractors are not equipped to organize and execute their works in a professional manner, hence triggering further problems such as defects, inadequate protection, excessive on-site fabrication, and poor work control. This is especially true where the specialist contractors procure materials and/or equipment for lower-tier subcontractors. Such inadequate incentives to avoid waste and/or protect materials may contribute to more construction debris.

\section{Applicable industrial management approaches}

It has long been contended in the manufacturing industry that an 'industrial production' philosophy is crucial for production waste reduction and the outcome of this reduction is an enhanced and smoothened flow of work within the production cycle (Schonberger, 1990; Plossl, 1991). Based on the structured interviews and deductive reasoning in this study as previously discussed, appropriate industrial management approaches were selected and are proposed to suitably attack the major causes that contribute to construction debris during the material control stage.

\subsection{Building Services Storage Principles}

With reference to the 'Principles of Site Material Management' suggested by Thomas et al. (2005), the 'Raw Material Storage Table’ extracted from guidebook as developed by Guthrie et al. (1999) and interview results and observations as obtained during the on-going study, the following 'BS Storage Principles' as tabulated in Table III are now proposed for the building services subsector in Hong Kong. These can play a role in an improved industrial management arrangement for reducing, even to a certain extent, the impacts of 'inappropriate site storage' and 'inadequate protection of materials', in addition to incorporating basic housekeeping and storage principles. 
Table III. Proposed 'BS Storage Principles' for the building services subsector

Major building services material types

\section{Description of 'Storage Principles'}

Options (examples)

\begin{tabular}{|c|c|}
\hline 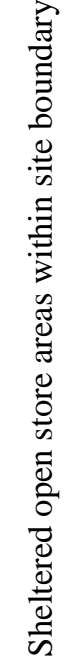 & 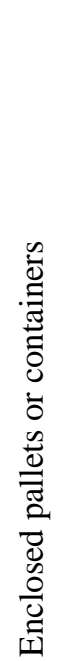 \\
\hline
\end{tabular}

1. Pipes \& conduits

Securely covered and stored in horizontal plane, supported off ground at appropriate intervals, segregated into separate types, sizes and grades and not protruding to obstruct traffic.

2. Pipe fittings \& valves

Securely covered and stored in containers according to types and sizes.

3. Thermal insulation Securely covered and stored away from dampness and segregated into types, sizes and grades with original packaged protections.

4. Metal sheets Securely covered and stored in horizontal plane in layers and supported off ground at appropriate intervals.

5. Electrical fittings (e.g. Securely protected and stored in boxes of separate types, sizes and brands, switchgears, fuses, protected from dampness by storage off ground and under cover.

MCBs, light fittings, etc)

6. Electrical cables

Securely protected and stored with the manufacturer's drums segregated in types, sizes and brands and protected from dampness by storage off ground and under cover.

7. Fire services fittings (e.g. Securely protected and stored in boxes of separate types, sizes and brands, detectors, breakglass protected from dampness by storage off ground and under cover. units, alarm bells, etc)

8. Packaged \& crated Securely protected and stored with the manufacturer's packaging and crating equipment in place.

9. Paints \& radiators Securely covered and stored in labelled and well packed containers of separate types, sizes and brands. Isolated and marked as dangerous/inflammable. 


\subsection{Barcoding and RFID Tracking System}

Modern technologies can also play a role in material management. For example, almost two decades ago, Stukhart (1990) identified barcoding as helpful for easy identification and retrieval of materials. Since then, the barcode asset management system has been recommended in the 'BSRIA Guidance Note - ACT 5/2002' to streamline the processes of procurement, delivery, installation and inspection on site, and to reduce time on site collecting, handling, monitoring, controlling and re-ordering effectively and productively (Dicks, 2003). Hawkins (2003) found that between 5-10\% of tools and equipment are normally lost on construction projects that do not employ an asset management system and much time is spent on stock-taking, report generation and material collection. Although relevant applications have been introduced to the construction industry since 1987 for material, plant and tool control (Bernold, 1991; Bell and McCullouch, 1998; Chen and Li, 2002), these are not evident in Hong Kong practice in general.

In the proposed system, each building component and equipment item can be coded and 'tagged' so that its status can be retrieved readily on line to save a tremendous amount of time and efforts in scheduling procurement processes, tracking construction materials, delivering directly to point of use or planned strategic locations, taking into account access paths and handling means, and transferring real-time data of receiving inspections via intranet and/or internet. As a result, the opportunities for damage, misuse, over-supply and vandalism can be significantly reduced, and more resources can then be diverted to the value-adding works to improve work productivity. Radio-Frequency Identification (RFID) technology is perceived as an emerging potential tool that has been increasingly applied in logistics and supply chain management in the last few years (Finkenzeller, 2003; Singh, 2003). This technology has more advantages than the barcoding system for material control and management, in particular of the wide range of building services materials because of its high data capacity and the ability to track different identities and parameters of the same type of materials.

Arising from deductive reasoning, a 'Material Tracking System' is proposed for building services material control in Hong Kong as conceptualised in Figure 2, so as achieve the function of a 'materials adviser' as long advocated by Illingworth and Thain (1987). The proposed 'Material Tracking System' is conceptualised to manage information relating to the material schedule, storage plan, inspection plan, site and resources availability, weather and traffic condition, etc.; and also take into account the proposed BS Storage Principles, before making appropriate delivery and storage decisions and generating reports and inspection logs. This framework and associated technology can assist in tracking 'scrap' in order to promote on-site sorting for recovery, reuse and recycle (3Rs) before sending to landfills. 
Figure 2. Envisaged 'Information Flow' in proposed material tracking system

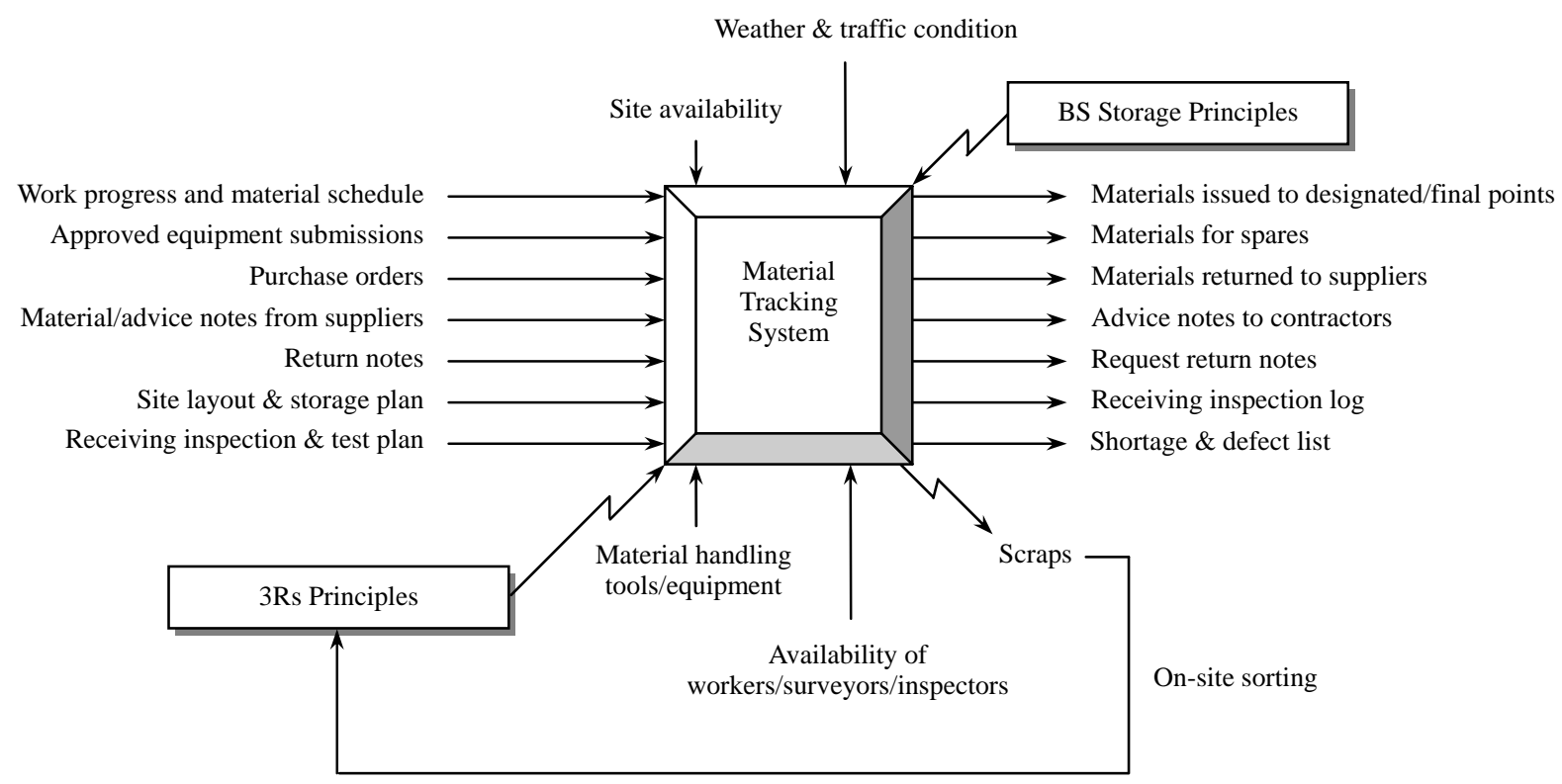

\subsection{Hybrid Push-Pull System}

As illustrated in the RSIs of the survey results in Table I, poor coordination in this particularly 'variable' and interdependent subsector of the construction industry may result in conflicts between crews and/or 'clashes' with other services, since they may compete for resources such as material handling equipment, storage space and/or the same access for on-site delivery, storage and installation. 'Conflicts' also arise when designated installation space is inadequate to accommodate the different services, such as pipes and cables. When conflicts are discovered in the field, it is usually too late to avoid some form of interruption and delay (Riley and Horman, 2001). In some cases, additional orders, demolitions, replacements and reworks for the installed works and/or procured materials may be required and this will contribute more to construction debris. Kauffman (1993) suggested that a highly complex system can be given a high degree of freedom in organization and management, instead of a formal management approach. Holzemer et al. (2000) pointed out that a combination of push and pull orders are useful for pushing long lead items such as ductwork components to site based on a master schedule whereas ductwork is fabricated based on pull order as and when the field foreman needs it. Taken together, these point to a role for a hybrid push-pull system that combines the best features of the two separate systems to reduce non value-adding reorders, demolitions, replacement and reworks in the building services subsector.

The pull system is also named the 'kanban' system and advocates of the pull system in the manufacturing industry have pointed extensively to the drawbacks of the push system and elaborated on how pull strategies overcome these drawbacks (Spearman and Zazanis, 1992; 
Womack and Jones, 1996). For this, at the planning stage, the design of prefabricated elements and preassemblies such as horizontal and vertical distribution systems, plant room piping arrangements, wiring loops, modular buildings, plant rooms, terminal unit assemblies, etc., (Wilson et al., 1998) should be determined and a pull system should be implemented in the off-site fabrication plant in response to the demand pulled by the downstream assembly phase at the site in order to reduce excessive or unnecessary orders of prefabricated elements.

Also, at the site level, the individual work progress and material schedule of one trade which generally authorizes and pushes the work centre, via the proposed Material Tracking System as in Figure 2, can quickly reduce any interference or conflict prior to material delivery, storage and installation at the same area. The downstream assembler of the work centre, for example concurrent ceiling works such as complex pipeworks, ductworks, risers, cabling and other assemblies, then authorizes the pull signal. In any case, on-site assembling of prefabricated components, materials or equipment will not begin unless the availability of space and resources, and all design uncertainties including dimensional tolerances and misinterpretation of services drawings are completely resolved. The assembler may pull on the 'rope' to smoothen variations or disruptions by requesting 'error-free' design and/or instruction. The actual work schedules and sub-processes between trades and crews are synchronised or physically aligned in response to the push, pull and suspension signals so as to reduce any probable conflicts before assembling. This seems to suggest that design decisions can be postponed until prerequisite work is completed and unobstructed access and workspaces are available (Tommelein and Ballard, 1997; Gil et al., 2001).

Figure 3 shows a typical process map for coordinating among various parties in air-conditioning installations. In case of clashes or conflicts between mechanical services relating to actual routing of ductwork, the site assembler may pull on the 'rope' to smoothen variations or disruptions and requesting immediate clarification about the design intent. The proposed Material Tracking System is conceptually incorporated as shown in Figure 3, for scheduling procurement processes, tracking construction materials, delivering directly to points of use or planned strategic locations and transferring real-time data of receiving inspections. 
Figure 3. A typical process map for coordinating among various parties in air-conditioning installations

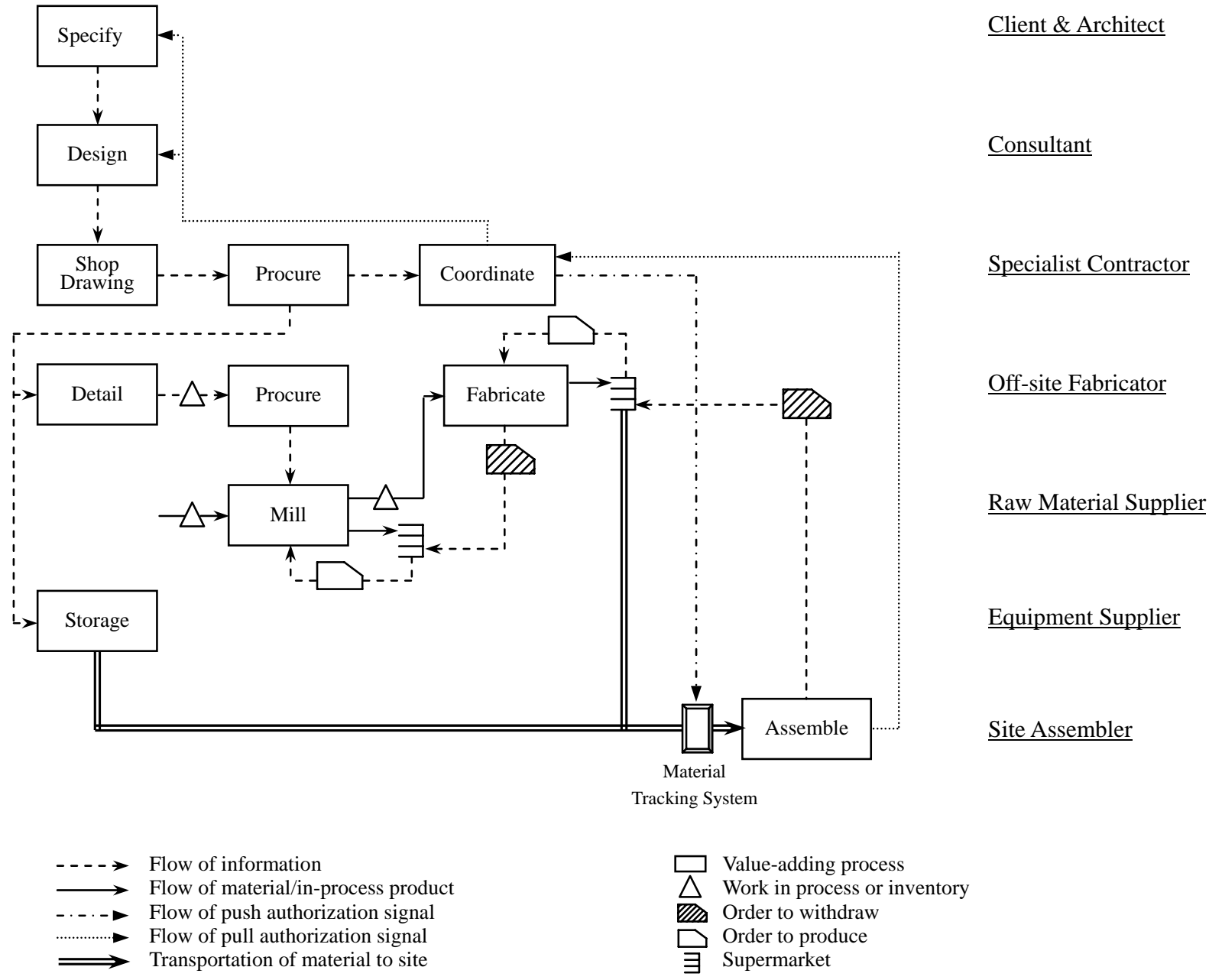

\section{Conclusion}

It is understood that production shortcomings contributing to the creation of construction debris cannot be eliminated. However, through proper management of the material control process, it is believed that a significant portion of the construction debris created by the building services subsector can be reduced or avoided.

This paper has identified the most significant causes that may cause construction debris in the material control stage by considering their respective relative frequency of occurrence and relative importance through a survey that incorporated in-depth interviews with experienced industry professionals. The most significant causes include: 'poor coordination of processes or trades', 'inappropriate site storage', and 'inadequate protection of materials'. While the findings in Hong Kong may reflect the situation elsewhere, it will be useful to undertake 
similar studies in other countries to identify country-specific causes and potential solutions as well.

The manufacturing industry has developed and established a number of principles in lean production in recent years that are believed to be equally applicable to the building services subsector to tackle the problems that cause construction debris. The authors have developed a set of 'Building Services Storage Principles' to alleviate the impacts of 'inappropriate site storage' and 'inadequate protection of materials'. It has been suggested that material management will be improved through adoption of the barcoding and RFID technologies and the proposed 'Material Tracking System'. The 'hybrid push-pull system' has been proposed to address the problem of coordination of processes and trades.

\section{Acknowledgements}

The authors are grateful to the industry practitioners who contributed their time and knowledge to the survey. The support of Grant HKU7138/05E of the Hong Kong Research Grants Council and Analogue Group of Companies are also gratefully acknowledged.

\section{References}

Assaf, S.A. and Al-Hejji, S. (2006), "Causes of delay in large construction projects", International Journal of Project Management, Vol. 24, pp. 349-357.

Bell, L.C. and McCullouch, B.G. (1998), "Bar code application in construction”, Journal of Construction Engineering and Management, Vol. 114 No. 2, pp. 263-278.

Bernold, L.E. (1991), “Testing bar-code technology in construction environment”, Journal of Construction Engineering and Management, Vol. 116 No. 4, pp. 643-655.

Bossink, B.A.G. and Brouwers, H.J.H. (1996), "Construction waste: Quantification and source evaluation”, Journal of Construction Engineering and Management, Vol. 122 No. 1, pp. 55-60.

Chang, P.C. (2007), “Study on the competitiveness indices of Taiwan's department stores”, Journal of the Chinese Institute of Industrial Engineers, Vol. 24 No. 5, pp. 414-427.

Chen, Z., Li, H. and Wong, C.T.C. (2002), “An application of bar-code system for reducing construction wastes”, Automation in Construction, Vol. 11, pp. 521-533.

Coventry, S. and Woolveridge, C. (2002), "Environmental good practice on site”, CIRIA C502, CIRIA.

Dicks, M. (2003), “Innovative M\&E data sheets”, BSRIA Guidance Note ACT 5/2002, BSRIA, Berkshire.

Ekanayake, E.L. and Ofori, G. (2004), “Building waste assessment score: design-based tool”, Building and Environment, Vol. 39 No. 2004, pp. 851-861.

Environmental Protection Department (EPD) (2007), “The problem - Introduction to 
Construction Waste", available at www.epd.gov.hk/epd/misc/cdm/introduction.htm/ (accessed 11 March 2007).

Environmental Protection Department (EPD) (2008), Monitoring of solid waste in Hong Kong - Waste statistics for 2007, Environmental Protection Department, Hong Kong.

Faniran, O.O. and Caban, G. (1998), "Minimizing waste on construction project sites engineering”, Construction and Architectural Management, Vol. 5 No. 2, pp. 182-188.

Finkenzeller, K. (2003), RFID Handbook: Fundamentals and applications in contactless smart cards and identification (2nd ed.), Wiley, Chichester, West Sussex.

Formoso, C.T., Soibelman, L., Cesare, C.D. and Isatto, E.L. (2002), "Material waste in building industry: Main causes and prevention”, Journal of Construction Engineering and Management, Vol. 128 No. 4, pp. 316-325.

Gavilan, R.M. and Bernold, L.E. (1994), "Source evaluation of solid waste in building construction”, Journal of Construction Engineering and Management, Vol. 120 No. 3, pp. 536-552.

Gil, N., Tommelein, I.D. and Kirkendall, R. (2001), "Modeling the design-build development process for a facility component”, Proceedings of the 9th annual conference of the international group for lean construction (IGLC-9), Singapore.

Guthrie, P., Woolveridge, A.C. and Patel, V.S. (1999), Waste minimization in construction: Site guide, CIRIA, London.

Hawkins, G. (2003), "Enabling technologies guide: How to use barcode asset management”, BSRIA Enabling Guide 2/2003, BSRIA, Berkshire.

Holzemer, M., Tommelein I.R. and Lin, S.L.A. (2000), "Materials and information flows from HVAC ductwork fabrication and site installation”, Proceedings of the 8th Annual Conference of the International Group for Lean Construction (IGLC-8), Brighton.

Illingworth, J.R. and Thain, K. (1987), “The control of materials and waste”, CIRIA Special Publication 56, CIRIA, Berkshire.

Illingworth, J.R. and Thain, K. (1988), "Materials management - Is it worth it”, CIRIA Special Publication 58, CIRIA, Berkshire.

Illingworth, J.R. (2000), Construction methods and planning (2nd ed.), E\&FN Spon, New York, NY.

Kauffman, S.A. (1993), The origins of order: Self organization and selection in evolution, Oxford University Press, NY.

Kometa, S.T., Olomolaiye, P.O. and Harris, F.C. (1994), “Attributes of UK construction clients influencing project consultants' performance”, Construction Management and Economics, Vol. 12 No. 3, pp. 433-443.

Lee, S.B. (2004), "A study on optimal lead time selection measures of the construction materials”, Korean Journal of Architecture Engineering, Vol. 4 No. 1.

Levin, J. and Fox, J.A. (2003), Elementary statistics in social research (9th ed), Allyn and 
Bacon, Boston.

Olnhoff, V. and Martin, A. (2003), "Recycling building services”, A BSRIA Guide BG 16/2003, BSRIA, Berkshire.

Plossl, G.W. (1991), Managing in the new world of manufacturing: How companies can improve operations to compete globally, Prentice-Hall, Englewood Cliffs, NJ.

Riley, D. R. and Horman, M. J. (2001), "Effects of design coordination on project uncertainty”, Proceedings of the 9th annual conference of the international group for lean construction (IGLC-9), Singapore.

Schonberger, R.J. (1990), Managing in the new world of manufacturing, Prentice Hall, Englewood Cliffs, NJ.

Stukhart, G. (1990), "Bar-code standardization in industrial construction”, Journal of Construction Engineering and Management, Vol. 123 No. 2, pp. 171-180.

Singh, N. (2003), "Emerging technologies to support supply chain management", Communications of the ACM, Vol. 46 No. 9, pp. 243-247.

Skoyles, E.F. (1976), "Material wastage: A misuse of resources”, Building Research and Practice, Vol. July/April, pp. 232-243.

Snook, K., Turner, A. and Ridout, R. (1995), "Recycling waste from the construction site”, Chartered Institute of Building.

Spearman, M.L. and Zazanis, M.A. (1992), "Push and pull production systems: Issues and comparisons”, Operations Research, Vol. 40 No. 3, pp. 521-532.

Tam, C.M., Deng, Z.M., Zeng, S.X. and Ho, C.S. (2000), "Quest for continuous quality improvement for public housing construction in Hong Kong”, Construction Management and Economics, Vol. 18 No. 4, pp. 437-446.

Thomas, H.R., Sanvido, V.E. and Sanders, S.R. (1989), "Impact of material management on productivity - A case study", Journal of Construction Engineering and Management, Vol. 115 No. 3, pp. 370-384.

Thomas, H.R., Riley, D.R. and Sanvido, V.E. (1999), "Loss of labor productivity due to delivery methods and weather", Journal of Construction Engineering and Management, Vol. 125 No. 1, pp. 39-46.

Thomas, H.R., Riley, D.R. and Messner, J.I. (2005), "Fundamental principles of site material management”, Journal of Construction Engineering and Management, Vol. 131 No. 7, pp. 808-815.

Tommelein, I.D. and Ballard, G. (1997), “Coordinating Specialists”, Technical Report 97-8, CEM Program, University of California, Berkeley.

Vaid, K.N. (1996), "Waste control of building materials in construction of mass housing project”, NICMAR Journal of Construction Management, Vol. 11 No. 4, pp. 367-394.

Wilson, D., Smith, M. and Deal, J. (1998), "Prefabrication and preassembly: Successful application in building engineering services”, BSRIA Briefing Note ACT 2/99, BSRIA, 
Berkshire.

Womack, J.P. and Jones, D.T. (1996), "Lean thinking: Banish waste and create wealth in your corporation”, Simon \& Schuster, New York.

\section{Corresponding Author}

Sammy K. M. Wan can be contacted at: sammywan@atal.com.hk 